\title{
Soya, maize and sorghum ready-to-use therapeutic foods are more effective in correcting anaemia and iron deficiency than the standard ready-to-use therapeutic food: randomized controlled trial
}

Peter Akomo ${ }^{1 *}$ (D), Paluku Bahwere ${ }^{2,5}$, Hitoshi Murakami $^{3}$, Chrissy Banda ${ }^{2}$, Elizabeth Maganga ${ }^{4}$, Sylvester Kathumba ${ }^{4}$, Kate Sadler ${ }^{2}$ and Steve Collins ${ }^{1,2}$

\begin{abstract}
Background: The prevalence of anaemia and iron deficiency (ID) among children with severe acute malnutrition (SAM) and their correction during nutritional rehabilitation are not well documented. This study assessed anaemia and ID prevalence and their predictors at start of SAM treatment, and the efficacy of their treatment and effect on gut health of two novel Ready-To-Use Therapeutic foods (RUTF) prepared from soybean, maize and sorghum (SMS) with (MSMS-RUTF) or without added milk (FSMS-RUTF) compared to those of the standard formulation prepared from peanut and milk (PM-RUTF).

Methods: This was a 3-arms parallel groups, simple randomised, controlled non-inferiority trial in 6-59 months old Central Malawian children with SAM. Anaemia was defined using altitude- and ethnicity-adjusted haemoglobin. Iron status was defined using soluble transferrin receptor (sTfR) and body iron stores (BIS). We used Pearson's chi-square test, t-test for paired or unpaired data, Kruskal-Wallis test for between-arm differences as appropriate and logistic regression to identify independent predictors of anaemia or iron deficiency anaemia (IDA).

Results: The sample size was 389. At admission, the prevalence [\%(95\%Cl)] of anaemia was $48.9(41.4-56.5) \%$ while that of ID and IDA were 55.7(48.6-62.5)\% and 34.3(28.2-41.0)\% when using sTfR criterion and 29.1(24.4-34.4)\% and 28.9(23.7-34.9)\% when using BIS criterion, respectively. At discharge, nutrition rehabilitation with SMS-RUTF was associated with the lowest prevalence of anaemia [12.0(6.9-20.3)\% for FSMS-RUTF, 18.2(11.9-26.8)\% for MSMS-RUTF and 24.5(15.8-35.9)\% for PM-RUTF; $p=0.023$ ] and IDA [7.9(3.4-17.3)\% for FSMS-RUTF, 10.9(4.8-22.6)\% for MSMS-RUTF and 20.5(10.7-35.5)\% for PM-RUTF; $p=0.028$ ]. SMS-RUTF was also associated with the highest increase in BIS [Change in BIS $(95 \% \mathrm{Cl})]$ among the iron deplete at admission $[6.2(3.7 ; 8.6), 3.2(0.8 ; 5.6), 2.2(0.2 ; 4.3)$ for the same study arms; Anova $p=0.045]$. Compared to P-RUTF, FSMS-RUTF had the highest adjusted recovery rate [OR $(95 \% \mathrm{Cl}=0.3(0.2-0.5)$ with $p<0.001$ for FSMS-RUTF and $0.6(0.3-1.0)$ with $p=0.068$ for MSMS-RUTF]. No effect of iron content on risk of iron overload or gut inflammation was observed.
\end{abstract}

Conclusions: Anaemia and ID are common among children with SAM. FSMS-RUTF is more efficacious in treating anaemia and correcting BIS among this group than PM-RUTF.

Trial registration: This study was registered on 15 April 2015 (PACTR201505001101224).

Keywords: Anaemia, Iron deficiency, Severe acute malnutrition, Ready-to-use therapeutic food, Iron, Milk

\footnotetext{
* Correspondence: peterakomo@validnutrition.org

'Valid Nutrition, Cuibín Farm, Derry Duff, Bantry, Co., Cork, Republic of Ireland

Full list of author information is available at the end of the article
}

C The Author(s). 2019 Open Access This article is distributed under the terms of the Creative Commons Attribution 4.0 International License (http://creativecommons.org/licenses/by/4.0/), which permits unrestricted use, distribution, and reproduction in any medium, provided you give appropriate credit to the original author(s) and the source, provide a link to the Creative Commons license, and indicate if changes were made. The Creative Commons Public Domain Dedication waiver (http://creativecommons.org/publicdomain/zero/1.0/) applies to the data made available in this article, unless otherwise stated. 


\section{Background}

Globally, severe acute malnutrition (SAM) affects about 16.4 million children aged 6-59 months, out of whom $23 \%$ currently access treatment using ready to use therapeutic food (RUTF) [1, 2]. Moreover, in Communitybased Management of Acute Malnutrition (CMAM), RUTF is the recommended diet for children in this age group being treated for SAM [3]. RUTF is a fortified energy dense food intended to cover all nutritional needs during recovery from SAM [3-5]. The most common formulation of RUTF is based on peanut and milk. However, research has been ongoing to develop alternative formulations that are equally effective and are cheaper and more acceptable in settings where peanut is not popular.

SAM is known to be a pluri-deficiency disease combining macronutrients and multiple micronutrients [6]. Thus, diets for SAM treatment should aim at correcting micronutrients deficiencies in addition to fulfilling requirements for catch up growth [6-9]. Anaemia is one of the most widespread nutritional deficiencies affecting over 1.6 billion people worldwide [10]. The burden varies from one study to another but the most recent representative estimates indicate that overall, $47.4 \%$ children below 5 years are affected worldwide with the highest prevalence of 64.6\% found among African children [10-13].

In children, anaemia (defined as a Haemoglobin below $110 \mathrm{~g} / \mathrm{L}$ ) is a clinical condition that results in weakness, difficulty in concentrating, susceptibility to infections, delayed cognitive and motor development and increased mortality [14, 15]. Anaemia can be classified into nutritional and non-nutritional anaemia, and is caused by several different factors including nutritional deficiencies, infections and inherited red blood cell disorders [16, 17]. Studies indicate that at least $50 \%$ of anaemia in children below 5 years of age from low and middle income countries is due to Iron deficiency (ID) $[13,14]$. This has led to various initiatives including supplementation and food fortification to increase intake of iron $[18,19]$.

Studies conducted in Africa and Asia have reported prevalence of over $80 \%$ of anaemia among SAM children admitted in tertiary care hospitals [20-23]. To our knowledge, no study has reported the prevalence among children admitted into Community-based Management of Acute Malnutrition (CMAM) programmes, a treatment approach that allows early initiation of nutrition rehabilitation $[24,25]$. The contribution of ID in anaemia during SAM is not well established, and available data suggest that the prevalence of ID may be context specific and depends on the co-existence of other factors contributing to the severity of SAM [26-29]. Despite the dearth of data on prevalence of IDA in SAM, the high prevalence of anaemia in children aged below 5 years and its serious clinical impacts underscore the importance of correcting ID during treatment of SAM.
Moreover, the high iron demand during catch-up growth makes recovering SAM cases particularly susceptible to ID. The presence of ID means that these children are at low risk of iron supplementation side effects even in malaria endemic areas as most side effects are observed in iron replete individuals [30, 31]. Indeed, the World Health Organisation still recommends routine iron supplementation for prevention and treatment of IDA in malaria endemic areas where prevalence of IDA is also usually high [31].

Absorption of iron is influenced by both dietary and physiological factors, with the former being determined mainly by the form of iron and by the presence of inhibitors and enhancers in a particular meal [32]. Among other factors, phytic acid, milk proteins and calcium, have been identified as nutritional factors inhibiting iron absorption, while ascorbic acid enhances its absorption [32-34]. These factors are present in varying amounts in formulations based on soybean, maize and sorghum [34], and their effects on anaemia and iron status are not well understood.

The currently recommended iron content of RUTF of $10-14 \mathrm{mg} / 100 \mathrm{~g}$ tries to balance the need to correct ID and provide iron to support the rapid tissue synthesis required for catch-up growth with the need to minimise the production of free radicals and the risk of enhancing bacterial growth and virulence $[3,35,36]$. However, a study has shown that RUTF providing $22 \mathrm{mg}$ per day of iron is less effective in maintaining or improving haemoglobin level than the therapeutic milk F100 providing $60 \mathrm{mg} /$ day of iron [37]. More recently, we published results indicating that an RUTF containing $43.8 \mathrm{mg} / 100 \mathrm{~g}$ iron is more effective in treating anaemia than an RUTF containing 10$14 \mathrm{mg} / 100 \mathrm{~g}$, however, the study was underpowered to demonstrate statistical difference in haemoglobin change in unadjusted analysis [38].

Concerns remain regarding the level of iron in therapeutic or supplementary food despite some studies showing the positive effect of iron supplementation on growth. These concerns are related to the potential side effects that some studies have attributed to iron fortified food of inducing an increase in the population of pathogenic bacteria in the gut that may induce intestinal inflammation [36]. Despite that a study conducted in South Africa showed that the iron form used in this study was not associated with increased bacterial growth, data comparing food with different iron contents are scarce making this a priority research area [36, 39].

This study aimed to determine the burden of anaemia among children with uncomplicated SAM and assess the efficacy of two novel RUTF formulations in correcting anaemia and ID during SAM treatment. The specific objectives were:

1. To determine the prevalence and risk factors of anaemia and ID among children with uncomplicated SAM, 
2. To analyse the impact of the novel recipes with reduced milk content on the efficacy of treating anaemia and ID, and

3. To examine the impact of increased iron intake on intestinal inflammation.

\section{Methods}

This study was embedded within a larger 3 -arms parallel group, simple randomised, controlled trial assessing the efficacy in treating SAM of two novel formulations of RUTF, using the standard peanut-milk RUTF as control. The methodological aspects were reported in detail previously in the paper presenting on the main findings of the randomised clinical trial in recovery rates from SAM [40]. Below we only include the aspects of the methods required to understand the findings of this paper.

\section{Study design}

This was a randomised clinical trial assessing the efficacy of 3 different formulation of RUTF in correcting anaemia and ID during the treatment of SAM. A subsample from the study population of the larger study, was randomly selected. The two principal outcomes of interest for this embedded study were: 1) prevalence and predictors of anaemia and ID at admission and at discharge; and 2) between arms difference in prevalence of anaemia and ID at discharge.

\section{Study setting and participants}

The study was conducted at 21 day-care feeding centres scattered in three districts in Central Malawi (Lilongwe, Dedza and Mchinji). The altitude of this area ranges from $578 \mathrm{~m}$ to $1300 \mathrm{~m}$ above sea level. The incidences of malaria, intestinal parasitic infestation, viral and bacterial infections are high during childhood [41, 42].

A subsample of 389 children aged 6-59 months diagnosed with SAM (mid upper arm circumference [MUAC] $<115 \mathrm{~mm}$ or bilateral pitting oedema of any degree) who also had good appetite and no medical complication, were selected from the larger study sample of 1347 children randomly allocated in the 3 treatments group by the simple randomization (ratio 1:1:1) based on a computer generated random list and using a closed envelope method as already described [40]. The subsample was selected using a predetermined schedule, where the phlebotomist nurse visited 3 to 4 sites per day and collected samples for baseline data in all those who were admitted $48 \mathrm{~h}$ before the visit. The collection of samples for baseline data was conducted across all the sites and was stopped when the required sample was reached. These same subjects were followed for collection of further samples at the subsequent sampling time-points.

\section{RUTF formulations}

The two new RUTF formulations were based on extruded soya, maize and sorghum, one containing no milk (FSMS-RUTF) and the other 9\% milk (MSMS-RUTF). The control RUTF (PM-RUTF) was based on peanuts and dried skim milk and contained $28 \%$ milk. As shown in Table 1, all the RUTFs were designed to meet the World Health Organisation (WHO) recommendations for RUTF mineral and vitamin levels [1] with the exception of iron and zinc. Iron, zinc and vitamin $C$ levels in FSMS-RUTF and MSMS-RUTF were increased to attain a phytic acid / iron molar ratio, ascorbic acid / iron weight ratio and zinc / iron weight ratio of $<2.5,3.0$ 16.0 and $0.8-3.5$, respectively to enhance iron and zinc absorption [43, 44]. Iron was in the form of ferrous sulphate monohydrate. All samples were identical in packaging except a colour code which was not understood by the participants and field implementers.

\section{Treatment protocol and Iron intake}

The nutrition and medical management of children in all study groups were similar and followed the Malawi national guidelines for the management of acute malnutrition with the exception of the day-care approach and the fact that children were allowed to eat the RUTF ad libitum. Study assistant nurses fed the children with the support of the caregivers and closely monitored intake and occurrence of symptoms and clinical signs such as appetite, diarrhoea, vomiting, abdominal pain, flatulence, fever, skin eruption, cough and respiratory distress. No iron was added to the treatment in case of mild or moderate anaemia. As per the national protocol, a blood transfusion was needed only if the haemoglobin was $<5 \mathrm{~g} / \mathrm{dl}$.

\section{Data collection and procedures}

Nutritional and morbidity parameters were monitored and recorded daily on specially designed forms. Blood samples for measurement of anaemia (haemoglobin, haematocrit and full blood count), iron status (ferritin, soluble transferrin receptor), retinol-binding protein and inflammation (Creactive protein, and alpha-1-acid glycoprotein) parameters were measured on admission and at discharge. Trained paediatric phlebotomists collected blood by antecubital or metacarpal venipuncture into appropriate tubes provided by the Lilongwe University of North Carolina research laboratory. All the blood specimens were immediately stored in CubeCooler ${ }^{\mathrm{Tr}}$ and kept at $4{ }^{\circ} \mathrm{C}$ [45] and delivered to the Lilongwe research laboratory within $6 \mathrm{~h}$. Samples for the measurement of haemoglobin, haematocrit and full blood count were analysed at the Lilongwe UNC laboratory immediately after delivery. For other parameters, samples were later shipped to Germany for the measurement of the 5 plasma proteins [ferritin, soluble transferrin receptor (sTfR), retinol-binding protein (RBP), C-reactive protein, 
Table 1 Nutritional composition of the study foods

\begin{tabular}{|c|c|c|c|c|}
\hline \multirow[b]{2}{*}{ Component } & \multirow[b]{2}{*}{ Unit } & \multicolumn{3}{|c|}{ Value / $100 \mathrm{~g}$} \\
\hline & & $\begin{array}{l}\text { FSMS- } \\
\text { RUTF }^{a}\end{array}$ & $\begin{array}{l}\text { MSMS- } \\
\text { RUTF }^{\text {b }}\end{array}$ & $\begin{array}{l}\text { PM- } \\
\text { RUTF }^{c}\end{array}$ \\
\hline Energy & $\mathrm{kcal}$ & 532 & 544 & 545 \\
\hline Protein & $g$ & 18.4 & 16.6 & 15.6 \\
\hline Fat & $g$ & 34.2 & 36.0 & 33.8 \\
\hline Fibre & $g$ & 7.1 & 4.8 & 1.9 \\
\hline Calcium & $\mathrm{mg}$ & 571 & 399 & 434 \\
\hline Phosphorus & $\mathrm{mg}$ & 503 & 493 & 351 \\
\hline Iron & $\mathrm{mg}$ & 35.1 & 31.6 & 10.5 \\
\hline Zinc & $\mathrm{mg}$ & 19.5 & 19.9 & 11.1 \\
\hline Selenium & $\mu \mathrm{g}$ & 26 & 25 & 27 \\
\hline Vitamin A & $\begin{array}{l}m g \\
R^{\mathrm{d}}\end{array}$ & 1.25 & 1.16 & 1.18 \\
\hline Thiamine & $\mathrm{mg}$ & 1.28 & 1.12 & 0.97 \\
\hline Riboflavin & $\mathrm{mg}$ & 1.63 & 1.97 & 3.20 \\
\hline Vitamin C & $\mathrm{mg}$ & 323 & 306 & 87 \\
\hline Vitamin B6 & $\mathrm{mg}$ & 0.99 & 0.93 & 0.66 \\
\hline Vitamin B12 & $\mu \mathrm{g}$ & 2.5 & 2.6 & 3.2 \\
\hline Folate & $\mu \mathrm{g}$ & 210 & 200 & 268 \\
\hline Niacin & $\mathrm{mg}$ & 7.54 & 7.94 & 7.6 \\
\hline Pantothenic acid & $\mathrm{mg}$ & 5.36 & 4.73 & 4.5 \\
\hline Biotin & $\mu \mathrm{g}$ & 86 & 81 & 80 \\
\hline Choline & $\mathrm{mg}$ & 90 & 70 & - \\
\hline Phytic acid & $g$ & 0.465 & 0.333 & 0.251 \\
\hline Phytic acid/Iron molar ratio & - & 1.12 & 0.89 & 2.02 \\
\hline Phytic acid/zinc molar ratio & - & 2.36 & 1.66 & 2.24 \\
\hline $\begin{array}{l}\text { Ascorbic acid//ron molar } \\
\text { ratio }\end{array}$ & - & 2.93 & 3.08 & 2.64 \\
\hline $\begin{array}{l}\text { Ascorbic acid/Iron weight } \\
\text { ratio }\end{array}$ & - & 9.20 & 9.68 & 8.29 \\
\hline $\begin{array}{l}\text { Calcium/phosphorus weight } \\
\text { ratio }\end{array}$ & - & 1.14 & 0.81 & 1.24 \\
\hline Zinc/copper weight ratio & - & 13.18 & 13.27 & 6.94 \\
\hline Zinc/iron weight ratio & - & 0.56 & 0.63 & 1.06 \\
\hline
\end{tabular}

${ }^{\mathrm{a}}$ FSMS-RUTF Milk Free Soya-Maize-Sorghum based Ready-To-Use Therapeutic Food

${ }^{\mathrm{b}}$ MSMS-RUTF Milk Soya-Maize-Sorghum based Ready-To-Use Therapeutic Food CPM-RUTF Peanut paste based Ready-To-Use Therapeutic Food

${ }^{\mathrm{d}} R E$ Retinol equivalent

and alpha-1-acid glycoprotein (AGP)]. At the Lilongwee laboratory, cells and plasma were separated within $24 \mathrm{~h}$ and the plasma was subsequently stored at $-80^{\circ} \mathrm{C}$ until shipping to Germany. Before shipping to Germany, the samples were unfrozen to allow for the transfer of $0.2 \mathrm{ml}$ of plasma into the VitMIN laboratory special pre-labelled storage tubes (Willstaett, Germany). All the samples were refrozen after the transfer. During shipping to Germany, the sample cold-chain was maintained using cooler boxes with dry ice.
A combined sandwich ELISA method was used to analyse 5 plasma proteins [ferritin, soluble transferrin receptor (sTfR), retinol-binding protein (RBP), C-reactive protein, and alpha-1-acid glycoprotein (AGP)] for determination of iron status [46].

To assess the impact of the different study RUTFs on gut inflammation, stools samples were collected from the subset of subjects from whom fresh stools could be obtained during the day of the visit by the samples collectors in plastic pots at baseline, at 3 weeks and at discharge for the measurement of calprotectin [47, 48]. A quantitative point-of-care chromatographic immunoassay kit (Quantum Blue ${ }^{\circ}$ Alpha laboratories, Hampshire, UK) was used for the measurement $[49,50]$. As per the manufacturer's instructions, two drops of homogenised stool were applied inside a plastic cassette and the cassette inserted into a portable electronic reader that displayed numerical value representing calprotectin concentration. The cassette reader was calibrated for each day of tests.

\section{Sample size}

Sample size was calculated to demonstrate the noninferiority of the new RUTFs in terms of haemoglobin change [40]. A total of 192 children studied at both admission and discharge were required to be $90 \%$ sure that the lower limit of a one-sided $95 \%$ confidence interval would be above the non-inferiority limit of $-0.5 \mathrm{~g} \mathrm{dl}-1$ indicating no difference between the arms. We increased this sample to a minimum of 300 children at admission and 225 (75 per arm) at discharge, to account for loss to follow up during nutrition rehabilitation due to defaulting, death, withdrawal of consent for blood collection, difficulties in blood collection or the requirement for a transfusion during treatment. This sample size was also sufficient for the determination of the prevalence of anaemia and ID at admission (calculated sample size $=292$ children assuming prevalence of $50 \pm 5 \%$ ) and discharge (calculated sample size of 233 children assuming prevalence of $25 \pm 5 \%$ ), the detection of a trend in the prevalence of anaemia at discharge equivalent to a $9 \%$ difference between groups and the existence of a difference in intestinal inflammation between the study arms.

\section{Variable transformation, adjustments and definitions}

Individual haemoglobin values were adjusted for altitude and ethnicity according to the methods by WHO [51] and Sullivan et al. [52]. The adjusted values were then used to define anaemia using the recommended cut-off for children aged 6-59 months of $110 \mathrm{~g} / \mathrm{L}[51,52]$.

As $\beta$-thalassemia trait is common among Malawian children, we calculated the Mentzer index to serve as a proxy of presence of $\beta$-thalassemia trait $[16,53,54]$. The index is calculated as the quotient of the mean corpuscular volume 
(MCV, in $\mathrm{fL}$ ) divided by the red blood cell count ( $\mathrm{RBC}$, in Millions per microliter). $\beta$-thalassemia trait was assumed if the index was $<13[53,54]$.

Plasma ferritin, soluble transferrin receptor (sTfR) and body iron stores (BIS) were used to describe iron status $[55,56]$. As these biomarkers are impacted by inflammation, they were adjusted using the inflammation biomarkers C-reactive protein and alpha-1-acid glycoprotein (AGP), according to the method proposed by Thurnham et al. [57]. We report iron sufficiency or deficiency using BIS (ratio of inflammation-adjusted Plasma Ferritin to inflammation-adjusted sT $f R$ [58] as a continuous variable with a BIS $<0 \mathrm{mg} \cdot \mathrm{kg}^{-1}$ indicating ID, a BIS between 0 and $2.9 \mathrm{mg} \cdot \mathrm{kg}^{-1}$ low iron status and a BIS $\geq 3 \mathrm{mg} \cdot \mathrm{kg}^{-1}$ indicating normal iron status. With adjusted sTfR, a value $>8.3$ $\mathrm{mg} / \mathrm{L}$ indicated ID while a value below this cut-off indicated absence of ID. We used Plasma Ferritin to define excess body iron stores or iron overload [59], taking a cutoff $>100 \mu / \mathrm{L}$ to define excess body iron stores [59].

\section{Data management and analysis}

Data were double entered by two enumerators into a customized Epidata database prepared for this study [60]. Quality of data entry was monitored by the supervisors who cross-checked a random selection of $10 \%$ of the records. Cleaned data were exported to stata-13 for analysis [61].

Some data for key biological markers of anaemia and iron status at discharge data collection point could not be obtained. An assessment of the reasons identified the following: discontinuation of collection of specimens for this sub-study when the number that the budget allowed to be included was reached; child dropout from the study; child death; and no return after being transferred for management of complication. The budget shortage was due to the unexpected rise in prices of the tests obliging us to reduce the sample of participants to be surveyed at discharge. The retrospective follow up of defaulters revealed that the defaults were attributed to relocation, death or mothers related reasons (fatigue due to advanced pregnancy, delivery of new baby, taking care of a hospitalised household member, divorce and farming obligations). As all these reasons are responsible of missing values that can be classified as "missing completely at random" we opted for complete case analysis approach that drops the missing values in the analysis $[62,63]$.

Means and standard deviations (SD), medians and interquartile ranges (IQR) or proportions and 95\% Confidence intervals $(95 \% \mathrm{CI})$ were used to describe the admission and discharge parameters, as appropriate. All 95\% CIs used clustered robust estimates of the variance to account for clustering at the level of the day care centre. Means were compared using t-test for paired or unpaired data, as appropriate, medians were compared using the Kruskal-Wallis test and proportions compared using the Pearson's chi-square test or the chi-square test for trend as appropriate. We used logistic regression to identify predictors of anaemia and IDA at admission and discharge. The predetermined candidate predictors were study arm, age, sex, MUAC of admission, presence of oedema at admission, adjusted haemoglobin of admission, length of stay in programme, daily RUTF intake and presence of $\beta$-thalassemia trait. The final model was obtained using the approach recommended by Greenland for the selection of variables [56]. We started with the full model with all the potential predictors listed above and thereafter manually removed nonsignificant variables one by one using the $p$-value and the change-in-estimate method [64]. Multivariable linear regression was used to obtain adjusted prevalence at discharge of anaemia, ID and IDA. The adjustment variables were gender, mother education level, anaemia at admission, iron status of admission as measured by BIS, and inflammation category of admission.

\section{Results}

Out of the 1303 children screened and accepted into the larger efficacy study, 389 were randomly selected for this embedded study of whom haemoglobin and iron status at admission was determined in 386 and 343 , respectively. The other 46 were excluded due to difficulties of obtaining adequate blood samples $(n=$ $43)$ and withdrawal of consent $(n=3)$. Recruitment and follow up for this study was conducted between September 2015 and June 2016. Table 2 presents the characteristics at admission of the enrolled children. The sample was balanced in terms of sex and breastfeeding status. There were more children below 24 months and the great majority had both parents alive with almost all the heads of the households being subsistence farmers. The three groups were different with regard to maternal education status, with PM-RUTF group having the lowest proportion of mothers with no education. Overall, less than $20 \%$ of the mothers reached the secondary level of education. There were marginally insignificant differences in gender and inflammation among the three groups. Access to safe drinking water was high but utilisation of insecticide treated net (ITN) was reported by less than 50\%. The two clinical forms of SAM were equally represented in the sample. The majority had some form of inflammation with elevated values of C-reactive protein or AGP. The Mentzer index classified only few of the children as probably having $\beta$ thalassemia trait. The between arms comparison showed that there was no difference in the other parameters evaluated. 
Prevalence of anaemia, iron deficiency and iron deficiency anaemia at admission

Out of the 386 children for whom haemoglobin was measured on admission (3 children withdrew consent after randomisation), anaemia was diagnosed in [\% (95\%CI)] 48.9(41.4-56.5)\%. Table 3 presents the distribution of anaemia per selected parameters. Children with $\beta$-thalassemia trait had low prevalence of anaemia when compared to those without the trait while those with inflammation at incubation and early convalescence had increased risk of anaemia when compared to those with no inflammation. Logistic regression analysis (detailed table provided as Additional file 1) confirmed the protective effect for anaemia of having $\beta$-thalassemia trait [Adjusted Odds Ratio (AOR) with absence of the trait as reference: $(0.4(0.2-0.9) ; p=0.036$ ] and high likelihood of anaemia in presence of inflammation at incubation phase [AOR (5.1(1.6-16.8); $p=0.007$ ] or at early convalescence phase [AOR (6.5(2.6-16.4); $p<0.001$ ]. The other predictors of anaemia were age (in months) at admission [AOR (0.94(0.90-0.97); $p=0.001$ ] and weight (in $\mathrm{kg}$ ) at admission [AOR (1.5(1.1-2.0); $p=0.016$ ].

Table 3 also presents observed ID prevalence. The prevalence is higher using sTfr criterion [\% (95\%CI)] [55.7(48.6-62.5)\%] than with BIS criterion [29.1(24.4$34.4) \%]$ but similar to that observed when the categories low BIS and depleted BIS are combined [55.4(50.0-60.7) $\%]$. Among children below 24 months of age, those still breastfed had a significantly higher prevalence of ID $(p=0.004)$. A third of all enrolled children had IDA and $>60 \%$ of the anaemia was associated with ID (Table 3). ID was also observed in non-anaemic children (Table 3). The independent predictors of IDA were largely similar to those for anaemia (Additional files 1 and 2); they included the absence of $\beta$-thalassemia trait (figures for IDA) [OR (0.4(0.2-0.9); $p=0.036$ ], presence of inflammation at incubation phase [OR (5.1(1.6-16.8); $p=0.007]$ and at early convalescence phase [OR (6.5(2.6-16.4); $p<0.001$ ], age (in months) at admission [OR (0.9(0.9-1.0); $p=0.001$ ], weight (in $\mathrm{kg}$ ) at admission [OR (1.5(1.1-2.0); $p=0.016$ ] all predicted both anaemia and IDA. Sex, utilisation of ITN, MUAC at admission and nutritional oedema status were not predictors of IDA (Additional file 2).

\section{Effect of RUTF used for nutritional rehabilitation on anaemia and iron deficiency}

In this study, iron intake was [mean (IQR)] 96.9 (71.0132.4), 84.3 (58.1-104.7), and 28.0 (22.2-37.7) $\mathrm{mg} \mathrm{d}^{-1}$ in children aged 6-23 mo at admission and 113.0 (87.2151.8), 101.8 (78.5-136.6), and 42.5 (34.8-51.2) $\mathrm{mg} \mathrm{d}^{-1}$ in children aged 24-59 mo at admission for the FSMSRUTF, MSMS-RUTF, and PM-RUTF arms, respectively.
From the 386 surveyed at admission, 266 (68.9\%) were assessed at discharge. The reasons for some not being assessed at discharge were reduction of the sample size because of budget constraint $(n=49)$, defaulting $(n=$ $54)$, not returned from referral $(n=12)$ and death $(n=$ 5). The proportion of missing data were 36.1(27.9$45.0) \%$ for the FSMS-RUTF arm, 29.0(20.6-38.5) \% for MSMS-RUTF arm and 28.8(21.7-36.8) \% for PMRUTF $(p=0.291)$. The distribution of reasons for missing data were not significantly different across study arms (data not shown).

Out of the 266 children assessed at discharge, 18.8 (13.4-25.7) \% were anaemic. The figure was 17.5 (12.1$24.7) \%$ for those discharged as cured $(n=257), 16.9$ $(11.2-24.6) \%$ for those without $\beta$-thalassemia trait at admission and discharged as cured $(n=219), 6.5(2.4-$ 16.7) \% for those without anaemia at admission $(n=$ $107)$ and $26.2(18.3-35.9) \%$ for those who were anaemic at admission $(n=107)$. Table 4 presents the data disaggregated by type of RUTF used for nutrition rehabilitation. The results show a linear trend in the prevalence of anaemia related to the milk content of the RUTF with the prevalence lowest in the FSMS-RUTF and highest in the PM-RUTF. This trend was seen in both those with and without anaemia at admission. A similar trend was observed when comparing haemoglobin change between admission and discharge (Additional file 3). FSMSRUTF was associated with greater increase of haemoglobin among children without the $\beta$-thalassemia trait $[\Delta$ $(\mathrm{SD})]=2.9(1.5)$ for FSMS-RUTF $(n=35), 2.6(2.0)$ for MSMS-RUTF $(n=36)$ and 2.0 (1.4) for PM-RUTF $(n=$ $42) ; p=0.0271]$. In logistic regression analysis adjusting for haemoglobin at admission and average daily intake of RUTF (Additional file 4), both FSMS-RUTF [OR $(95 \% \mathrm{CI}=0.3(0.2-0.5) ; p<0.001]$ and MSMS-RUTF [OR $0.6(0.3-1.0) ; p=0.068$ ] were independently associated with reduced likelihood of being anaemic at discharge and there was a statistically significant linear trend associated with the milk content of the products $(p<0.001)$.

Regarding ID and IDA, Table 4 also shows that FSMSRUTF arm had higher cure rates and lower frequency of new episodes for both ID and IDA than the two other arms. The linear trend was also statistically significant.

Figure 1 shows the distribution of individuals' values of BIS at admission and discharge according to iron status at admission. Overall, there was an increase in BIS but with variations according to type of RUTF used for nutrition rehabilitation and according to BIS category at admission (Additional file 5). Some children with normal BIS at admission became iron deficient during the course of nutrition recovery. For children with normal iron stores, the BIS decreased in all study arms by an average $(\Delta(95 \% \mathrm{CI})$ of $-0.9(-1.9 ; 0.1)$ for the FSMSRUTF arm $(p=0.074),-0.3(-1.9 ; 1.3)$ for the MSMS- 
Table 2 Characteristics of study subjects at admission according to study arms ${ }^{a}$

\begin{tabular}{|c|c|c|c|c|c|}
\hline Parameter & $\begin{array}{l}\text { TOTAL } \\
n(\%)\end{array}$ & FSMS-RUTF $n(\%)$ & MSMS-RUTF $n(\%)$ & PM-RUTF $n(\%)$ & $p$-value \\
\hline \multicolumn{6}{|l|}{ Sex } \\
\hline Male & $202(51.5)$ & $76(56.7)$ & $47(43.1)$ & $79(53.0)$ & \multirow[t]{2}{*}{0.097} \\
\hline Female & $190(48.5)$ & $58(43.3)$ & $62(56.7)$ & $70(47.0)$ & \\
\hline \multicolumn{6}{|l|}{ Age } \\
\hline$<24 \mathrm{mo}$ & $227(57.9)$ & $71(53.0)$ & $67(61.5)$ & $89(59.7)$ & \multirow[t]{2}{*}{0.350} \\
\hline$>24 \mathrm{mo}$ & $165(42.1)$ & $63(47.0)$ & $42(38.5)$ & $60(40.3)$ & \\
\hline \multicolumn{6}{|l|}{ Breastfeeding status } \\
\hline Breastfed & $188(48.1)$ & $59(55.6)$ & $55(50.5)$ & $74(49.7)$ & \multirow[t]{2}{*}{0.567} \\
\hline Not breastfed & $203(51.9)$ & $74(44.4)$ & $54(49.5)$ & $75(50.3)$ & \\
\hline \multicolumn{6}{|l|}{ Highest level of education of mother } \\
\hline None & $163(41.6)$ & $56(41.8)$ & $34(31.2)$ & $73(49.0)$ & \multirow[t]{3}{*}{0.040} \\
\hline Primary & $153(39.0)$ & $52(38.8)$ & $54(49.5)$ & 47 (31.5) & \\
\hline Secondary or higher & $76(19.4)$ & $26(19.4)$ & $21(19.3)$ & $29(19.5)$ & \\
\hline \multicolumn{6}{|c|}{ Principal activity of head of the household } \\
\hline Subsistence farming & $368(93.9)$ & $126(94.0)$ & $103(94.5)$ & $139(93.3)$ & \multirow[t]{2}{*}{0.920} \\
\hline Others & $24(6.1)$ & $8(6.0)$ & $6(5.5)$ & $10(6.7)$ & \\
\hline \multicolumn{6}{|l|}{ Father vital status } \\
\hline Dead & $4(1.0)$ & $1(0.7)$ & $0(0.0)$ & $3(2.0)$ & \multirow[t]{2}{*}{0.262} \\
\hline Alive & $388(99.0)$ & $133(99.3)$ & $109(100)$ & $146(98.0)$ & \\
\hline \multicolumn{6}{|l|}{ Mother vital status } \\
\hline Dead & $7(1.8)$ & $3(2.8)$ & $0(0.0)$ & $4(2.7)$ & \multirow[t]{2}{*}{0.244} \\
\hline Alive & $385(98.2)$ & $131(97.8)$ & $109(100)$ & $145(97.3)$ & \\
\hline \multicolumn{6}{|l|}{ Drinking water source } \\
\hline Improved & $297(76.6)$ & $101(75.9)$ & $81(75.0)$ & $115(78.2)$ & \multirow[t]{2}{*}{0.817} \\
\hline Unimproved & $91(23.4)$ & $32(24.1)$ & $27(25.0)$ & $32(21.8)$ & \\
\hline \multicolumn{6}{|l|}{ Use of insecticide treated net } \\
\hline No insecticide treated net used & $173(44.6)$ & $52(39.4)$ & $50(46.3)$ & $71(48.0)$ & \multirow[t]{2}{*}{0.324} \\
\hline Using insecticide treated net & $215(55.4)$ & $80(60.6)$ & $58(53.7)$ & $77(52.0)$ & \\
\hline \multicolumn{6}{|l|}{ Inflammation status } \\
\hline No inflammation & $41(11.7)$ & $13(11.0)$ & $15(15.3)$ & $13(9.7)$ & \\
\hline Incubation & $16(4.6)$ & $5(4.2)$ & $8(8.2)$ & $3(2.2)$ & \\
\hline early convalescence & $178(50.9)$ & $59(50.0)$ & $53(54.1)$ & $66(49.3)$ & \multirow[t]{2}{*}{0.086} \\
\hline late convalescence & $115(32.8)$ & $41(34.8)$ & $22(22.4)$ & $52(38.8)$ & \\
\hline \multicolumn{6}{|l|}{ Mentzer index ${ }^{\mathrm{b}}$} \\
\hline < 13: beta-thalassemia likely & $60(15.3)$ & $19(14.3)$ & $20(18.4)$ & $21(14.1)$ & \multirow[t]{2}{*}{0.591} \\
\hline$\geq 13$ : beta-thalassemia unlikely & $331(84.7)$ & $114(85.7)$ & 89 (81.6) & $128(85.9)$ & \\
\hline \multicolumn{6}{|l|}{ Clinical form of SAM ${ }^{C}$ at admission } \\
\hline Oedematous & $217(55.4)$ & $72(53.7)$ & $64(58.7)$ & $81(54.4)$ & \multirow[t]{2}{*}{0.704} \\
\hline Non-oedematous & $175(44.6)$ & $62(46.3)$ & $45(41.3)$ & $68(45.6)$ & \\
\hline
\end{tabular}

" $p=$ value of chi-square test comparing the 3 arms

a Study arms: FSMS-RUTF Milk Free Soya-Maize-Sorghum based Ready-To-Use Therapeutic Food, MSMS-RUTF Milk Soya-Maize-Sorghum based Ready-To-Use Therapeutic Food and PM-RUTF Peanut milk based Ready-To-Use Therapeutic Food

${ }^{\mathrm{b}}$ Mentzer index mean corpuscular volume/red blood cell count

'SAM severe acute malnutrition 
Table 3 Prevalence of anaemia, iron deficiency and iron deficiency anaemia at admission

\begin{tabular}{|c|c|c|c|}
\hline Criteria & $n$ & $\%$ & $(95 \% \mathrm{Cl}$ \\
\hline \multicolumn{4}{|l|}{ Prevalence of anaemia } \\
\hline All children & 386 & 48.9 & $(41.4-56.5)$ \\
\hline \multicolumn{4}{|l|}{ Anaemia by admission age } \\
\hline$<24$ months & 226 & 50.3 & $(43.3-56.7)$ \\
\hline$\geq 24$ months & 160 & 46.9 & $(39.7-57.3)$ \\
\hline \multicolumn{4}{|l|}{ Anaemia by sex } \\
\hline Boys & 200 & 44.5 & $(34.2-55.2)$ \\
\hline Girls & 186 & 53.7 & $(45.0-62.2)$ \\
\hline \multicolumn{4}{|l|}{ Prevalence of iron deficiency } \\
\hline \multicolumn{4}{|l|}{ By plasma sTfR (> $8.3 \mathrm{mg} / \mathrm{L})$} \\
\hline All children & 343 & 55.7 & $(48.6-62.5)$ \\
\hline No $\beta$-thalassemia & 290 & 53.4 & $(45.0-61.7)$ \\
\hline No inflammation & 41 & 64.9 & $(44.4-81.0)$ \\
\hline No inflammation and $\beta$-thalassemia & 29 & 58.6 & $(36.5-77.7)$ \\
\hline Children $<24$ months still breastfed & 154 & 70.8 & $(62.9-77.6)$ \\
\hline Children $<24$ months not breastfed & 46 & 45.6 & $(32.2-59.7)$ \\
\hline Among non-anaemic & 177 & 42.9 & $(35.5-50.6)$ \\
\hline Among anaemic children & 166 & 69.3 & $(61.7-76.2)$ \\
\hline \multicolumn{4}{|l|}{ By body iron stores criterion } \\
\hline Low iron stores ( 0 and $2.9 \mathrm{mg} \cdot \mathrm{kg}^{-1}$ ) & 343 & 29.1 & $(24.4-34.4)$ \\
\hline Depleted iron stores $\left(<0\right.$ mg. $\left.\mathrm{kg}^{-1}\right)$ & 343 & 26.2 & $(21.8-31.1)$ \\
\hline \multicolumn{4}{|l|}{ Low or depleted iron stores $\left(<3 \mathrm{mg} \cdot \mathrm{kg}^{-1}\right)$} \\
\hline Among all children & 343 & 55.4 & $(50.0-60.7)$ \\
\hline Among non-anaemic children & 177 & 52.0 & $(44.3-59.5)$ \\
\hline Among anaemic children & 166 & 59.0 & $(51.1-66.6)$ \\
\hline \multicolumn{4}{|l|}{ Prevalence of iron deficiency anaemia } \\
\hline By plasma sTfR criterion(> $8.3 \mathrm{mg} / \mathrm{L}$ ) & 343 & 33.5 & $(28.5-38.8)$ \\
\hline By body iron stores criterion $(<3 \mathrm{mg} / \mathrm{kg}$ ) & 343 & 28.6 & $(23.8-33.7)$ \\
\hline
\end{tabular}

RUTF arm $(p=0.686)$ and $-2.2(-3.3 ;-1.1)$ for the PM-RUTF arm $(p<0.001)$. By contrast, children with BIS indicative of low iron status or iron deficiency at admission all showed significant increases in iron stores during treatment with observed changes $(\Delta(95 \% \mathrm{CI})$ of $2.2(0.8 ; 3.5), 1.9(0.9 ; 2.8)$ and $1.1(0.1 ; 2.1)$ for FSMSRUTF $(p=0.003)$, MSMS-RUTF $(p=0.001)$ and PMRUTF ( $p=0.033$ ) respectively in the low iron status category and $6.2(3.7 ; 8.6)$ for FSMS-RUTF group ( $p<$ $0.001), 3.2(0.8 ; 5.6)$ for MSMS-RUTF $(p=0.011), 2.2$ (0.2; 4.3) PM-RUTF $(p=0.034)$ in the iron depleted category. The frequency of children with the inflammationadjusted Plasma Ferritin at discharge $>100 \mu \mathrm{g} / \mathrm{L}$ indicative of excess iron reserve were $1.6 \%(1 / 64)$ in the FSMS-RUTF arm, $4.3 \%(2 / 46)$ in the MSMS-RUTF arm and $4.8 \%(4 / 84)$ in the PM-RUTF arm $(p=0.559)$. For children with $\beta$-thalassemia trait, only one had adjusted
Plasma Ferritin $>100 \mu \mathrm{g} / \mathrm{L}$ at discharge. This child was from the PM-RUTF arm.

\section{Effect of RUTF used for nutrition rehabilitation on gut inflammation}

Gut inflammation as measured by concentration of calprotectin in stools was high in all study arms at admission and remained high after 3 weeks of treatment and at discharge, with no statistically significant difference across the study arms. The median values of the calprotectin in stools at admission [median (interquartile range): 233.0(110.0-442.0) $\mu \mathrm{g} / \mathrm{g}$ of stool for FSMS-RUTF, 278.0(91.0-540.0) $\mu \mathrm{g} / \mathrm{g}$ of stools for MSMS-RUTF, 307.0(192.0-560.0) $\mu \mathrm{g} / \mathrm{g}$ of stools for PM-RUTF; $p=0.385$ ] and discharge [median (interquartile range): $146.0(69.5-308.0) \mu \mathrm{g} / \mathrm{g}$ of stools for FSMSRUTF, 247.0(94.0-406.0) $\mu \mathrm{g} / \mathrm{g}$ of stools for MSMS-RUTF, 213.5(87.5-637.5) $\mu \mathrm{g} / \mathrm{g}$ of stools for PM-RUTF; $p=0.263$ ] remained well above the cut-off for presence of gut inflammation of $100 \mu \mathrm{g} / \mathrm{g}$ of stool until discharge (Fig. 2).

\section{Discussion}

In this study, we have shown that prevalence of anaemia, ID and IDA are high in Malawian children with uncomplicated SAM admitted into a CMAM programme, above the WHO criterion of $40 \%$ defining a severe public health problem and much higher than the $29 \%$ reported by the most recent community-based study among Malawian children below 5 years $[16,65]$. Similar high prevalence of anaemia among children with SAM have been reported in other countries and continents $[66,67]$, indicating that SAM children should be considered as an "at risk group" for anaemia.

Emerging evidence suggests that anaemia in low income countries is multifactorial with dietary factors an important cause [20, 28, 29,67]. Our results indicate that a high proportion of Malawian children who develop SAM during hunger seasons, which occur around November to March when family food reserves are largely depleted, have IDA and a pre-existing iron deficiency before developing SAM indicating that the usual factors causing iron deficiency are also in play for children with SAM $[26,68-70]$. This finding contradicts the historical view that children with SAM usually have elevated body iron at diagnosis and supports the current practise of presumptive treatment of IDA during treatment of SAM.

This study also demonstrates that the content of cow's milk in RUTF is inversely related to the product's efficacy in treating anaemia and replenishing Body Iron Stores (BIS). This is more demonstrated by the difference in efficacy between the two SMS-based formulations which had similar phytic acid/iron and ascorbic acid / iron molar ratios and ascorbic acid / iron weight ratios. It is well known that casein, whey protein and 
Table 4 Adjusted prevalence of anaemia, ID and IDA at discharge across study arms ${ }^{\mathrm{a}}$

\begin{tabular}{|c|c|c|c|c|c|c|c|}
\hline \multirow[t]{2}{*}{ 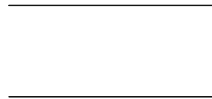 } & \multirow[t]{2}{*}{$n$} & \multirow[t]{2}{*}{$\%(95 \% \mathrm{Cl})^{f}$} & \multicolumn{2}{|c|}{ Unadjusted difference } & \multicolumn{2}{|c|}{ Adjusted difference ${ }^{b}$} & \multirow{2}{*}{$\begin{array}{l}p^{-} \\
\text {value }^{\mathrm{e}}\end{array}$} \\
\hline & & & Diff $^{9}$ & $(95 \% \mathrm{Cl})$ & Diff & $(95 \% \mathrm{Cl})$ & \\
\hline \multicolumn{8}{|c|}{ Prevalence of anaemia $^{c}$ at discharge } \\
\hline \multicolumn{8}{|l|}{ All children } \\
\hline FSMS-RUTF & 83 & $12.0(6.9-20.3)$ & Base & & Base & & \\
\hline MSMS-RUTF & 77 & $18.2(11.9-26.8)$ & 6.1 & $(-0.6 ; 18.3)$ & 7.6 & $(-3.9 ; 19.0)$ & 0.195 \\
\hline PM-RUTF & 106 & $24.5(15.8-35.9)$ & 12.5 & $(1.2 ; 23.7)$ & 12.6 & $(2.1 ; 23.1)$ & 0.019 \\
\hline \multicolumn{8}{|c|}{ Without anaemia at admission } \\
\hline FSMS-RUTF & 43 & $4.6(1.0-19.2)$ & Base & & Base & & \\
\hline MSMS-RUTF & 35 & $5.7(0.8-31.5)$ & 1.1 & $(-9.1 ; 11.2)$ & 5.7 & $(-5.2 ; 16.6)$ & 0.303 \\
\hline PM-RUTF & 59 & $11.9(5.5-23.7)$ & 7.2 & $(-3.6 ; 18.0)$ & 7.1 & $(-2.4,16.5)$ & \\
\hline \multicolumn{8}{|c|}{ With anaemia at admission } \\
\hline FSMS-RUTF & 38 & $18.4(10.0-31.3)$ & Base & & Base & & \\
\hline MSMS-RUTF & 40 & $30.0(20.0-42.3)$ & 11.6 & $(-8.8 ; 32.0)$ & 12.8 & $(-0.3 ; 35.0)$ & 0.254 \\
\hline PM-RUTF & 45 & $40.0(26.0-55.9)$ & 21.6 & $(1.7 ; 41.4)$ & 22.2 & $(2.9 ; 41.5)$ & 0.024 \\
\hline \multicolumn{8}{|c|}{ Prevalence of iron deficiency ${ }^{d}$ at discharge } \\
\hline \multicolumn{8}{|l|}{ All children } \\
\hline FSMS-RUTF & 64 & $42.2(29.1-56,4)$ & Base & & Base & & \\
\hline MSMS-RUTF & 46 & $60.9(49.4-71.2)$ & 18.7 & $(-0.1 ; 37.5)$ & 25.3 & $(6.6 ; 44.0)$ & 0.008 \\
\hline PM-RUTF & 84 & $58.3(44.9-70.7)$ & 16.1 & $(-0.1 ; 34.2)$ & 20.6 & $(4.8 ; 36.4)$ & 0.011 \\
\hline \multicolumn{8}{|c|}{ Iron deficient at admission } \\
\hline FSMS-RUTF & 36 & $47.2(29.5-65.7)$ & Base & & Base & & \\
\hline MSMS-RUTF & 21 & $85.7(56.1-96.6)$ & 38.5 & $(15.5 ; 61.2)$ & 38.7 & $(17.7 ; 59.6)$ & $<0.001$ \\
\hline PM-RUTF & 43 & $83.7(73.9-90.3)$ & 36.5 & $(16.2 ; 56.7)$ & 35.0 & $(14.7 ; 55.2)$ & 0.001 \\
\hline \multicolumn{8}{|c|}{ Prevalence of iron deficiency anaemia at discharge } \\
\hline \multicolumn{8}{|l|}{ All children } \\
\hline FSMS-RUTF & 63 & $7.9(3.4-17.3)$ & Base & & Base & & \\
\hline MSMS-RUTF & 46 & $10.9(4.8-22.6)$ & 2.9 & $(-8.4 ; 14.3)$ & 2.9 & $(-8.5 ; 14.4)$ & 0.611 \\
\hline PM-RUTF & 83 & $20.5(10.7-35.5)$ & 12.5 & $(1.4 ; 23.6)$ & $10 ; 8$ & $(0.6 ; 21.1)$ & 0.039 \\
\hline
\end{tabular}

${ }^{a}$ Study arms: FSMS-RUTF Milk Free Soya-Maize-Sorghum Based Ready-To-Use Therapeutic Food, MSMS-RUTF Milk Soya-Maize-Sorghum Based Ready-To-Use Therapeutic Food and PM-RUTF Peanut milk based Ready-To-Use Therapeutic Food

badjusted for age, gender, mother level of education, anaemia at admission and presence of iron deficiency using the body iron store based criterion

'Anaemia diagnosed based on altitude- and ethnicity-corrected haemoglobin

dIron status according to inflammation-corrected soluble transferrin receptor values

${ }^{e} p$-value for the adjusted difference obtained by multivariable linear regression

${ }^{\mathrm{f}} \mathrm{Cl}$ confidence interval

${ }^{9}$ Diff difference

calcium, that are all abundant in cow's milk, inhibit iron absorption [15, 33, 71]. In this study, the milk-free FSMS-RUTF product containing $35.1 \mathrm{mg} F \mathrm{Fe} / 100 \mathrm{~g}$ performed significantly better than MSMS-RUTF containing 9.3\% cow's milk and comparable iron content of $31.6 \mathrm{mg} / 100 \mathrm{~g}$. In turn, the MSMS-RUTF performed significantly better than the standard PM-RUTF product containing $28.2 \%$ cow's milk and $10.5 \mathrm{mg} \mathrm{Fe} / 100 \mathrm{~g}$. These results are similar to those of a study conducted in Burkina Faso that also reported a better absorption of zinc when provided as tablet than when given concurrently with a low dose lipid-based nutrient supplement
(LNS) containing cow's milk powder [72]. In order to achieve optimal mineral delivery through ready to use foods, these findings suggest that further research is needed to determine the optimal balance between levels of mineral fortification and the composition of the food including the content of milk.

The superior performance of the pulse/grain-based formulations compared to the milk-based formulation demonstrates that the high content of phytates in cereals and pulses is not necessarily a barrier to using these ingredients in the manufacture of RUTFs. To address this problem, the iron and vitamin $\mathrm{C}$ levels in the two new 


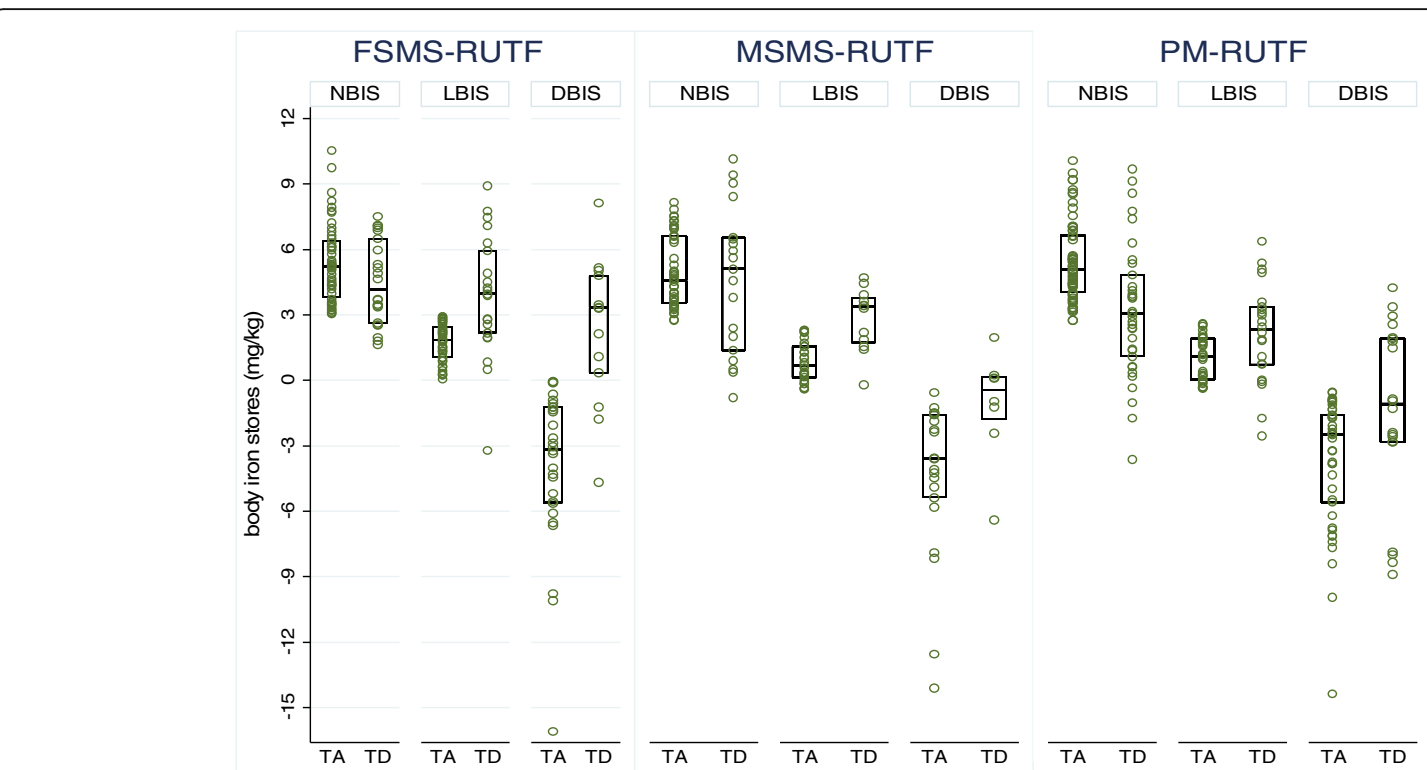

Fig. 1 Body iron stores at admission (TA) and discharge (TD) according to study arm and body iron status category of admission. Study arms: FSMS-RUTF = Milk Free Soya-Maize-Sorghum Based Ready-To-Use Therapeutic Food, MSMS-RUTF = Milk Soya-Maize-Sorghum Based Ready-To-Use Therapeutic Food and PM-RUTF = Peanut milk based Ready-To-Use Therapeutic Food; Body iron stores categories: NBIS=Normal body iron stores/ no iron deficiency, LBIS = Low body iron stores, DBIS = Depleted Iron stores; Assessment time: TA = at admission and TD = at discharge

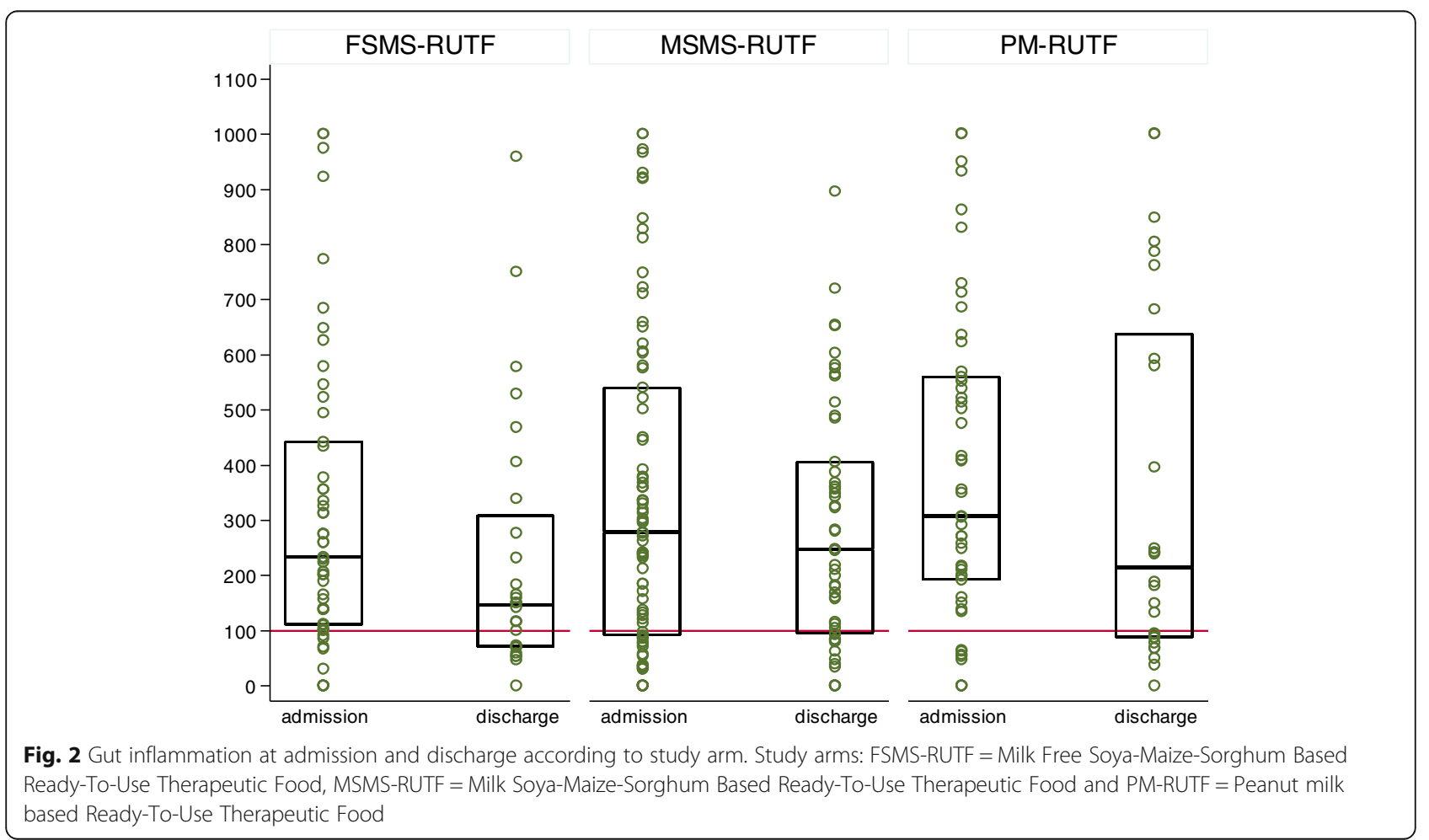


RUTF formulations were increased to achieve phytic acid: iron molar ratio and vitamin $\mathrm{C}$ : iron weight ratios that are optimum for iron absorption [43, 44, 73].

A potential problem with increasing the level of iron is that unabsorbed iron could change the gut microbiome and promote the growth of pathogens [47, 74-76]. This is particularly relevant as this study was conducted in a malaria-endemic setting where some studies have suggested that iron supplementation may enhance morbidity in iron replete children [77] and controversy exists over whether foods in such settings should be fortified with iron. However as reported in our previous study, no differences in morbidity was observed in our studies between the high iron and low iron RUTF arms, indicating that the iron content of the foods was not associated with an increased frequency of episodes of fever [40]. This finding mirrors that of a previous study using an LNS with a much higher level of iron for a long period of 6 months [78].

The absence of any differences in stools calprotectin concentration, a marker of intestinal inflammation between the study arms at any of the three points of measurement also indicates that the higher levels of iron were not associated with increased gut mucosal inflammation [47, 79]. These findings again reflect those of a study conducted among South African children that concluded that supplementation with ferrous sulphate had no detrimental effect on microbiota [39]. However, it is interesting to note that high faecal calprotectin levels persisted in all three study arms, a finding reported elsewhere in children recovering from SAM [80] and suggestive of persistent intestinal inflammation that is not completely resolved by the treatment. Although several studies have shown that nutrition rehabilitation with RUTF is associated with improvement of the microbiota, the improvement is incomplete and transient $[81,82]$. In children with cystic fibrosis who have similar gut mucosal abnormalities to those seen in SAM, the use of probiotics has been associated with improvements in mucosal structure $[83,84]$ suggesting that adding probiotics into RUTF may help to achieve sustained normalisation of intestinal mucosa. Interestingly, 8 years ago we published a pioneering study that assessed the effect of adding probiotic in RUTF and yielded promising results suggesting positive effect on mortality [85].

Increasing the iron was also not associated with iron overload and in this study changes in BIS were inversely proportional to BIS at the start of treatment, demonstrating that in the presence of tissue ID there is an upregulation of intestinal absorption and vice versa. This indicates that tissue iron status in children with SAM still plays the central role in regulating (upregulating and downregulating) iron intestinal absorption and mobilisation from body stores [86-89]. As a result, during the usual duration of CMAM treatment biological regulation mechanisms appear able to keep tissue iron concentration below the excess cut-off and the risk of excess body iron stores is limited. This finding contradicts observations gathered before the advent of CMAM that reported a deregulation of iron metabolism at the time of admission into therapeutic feeding programmes $[24,86$, 90]. In practice, it means that the fear of an increased absorption of iron during SAM is not a reason to prevent upward revision of the recommended iron density for RUTF used for uncomplicated SAM.

An important finding from this study is that none of the formulations used, even the higher iron non-milk formulation, adequately corrected ID and IDA by the time of reaching CMAM anthropometric discharge criteria in a substantial proportion of children. This is a serious deficiency. The improved performance of the plant-based RUTFs containing higher quantities of iron and the absence of negative side effects of increasing the iron content $[38,40]$ strongly suggest that the current recommendation on iron density of RUTF needs to be revised upwards [3].

We also found that the iron status of some children deteriorated during treatment, particularly with the WHO recommended lower iron formula, indicating that the recommended level of iron in RUTF is less effective in covering the increased need for iron during rapid catch up [91]. This finding is in line with that of an earlier study conducted in Senegal that showed that the currently recommended iron density in RUTFs is not sufficient to cover the needs of children with SAM during the period of rapid catch up growth, particularly in those children with higher weight gain velocities [37].

This study also provided evidence that current anthropometric discharge criteria are not a good proxy for attainment of homeostasis for iron, with anthropometric discharge criteria being met before a significant proportion of children attains replenished BIS, especially those who were depleted at the start of treatment. Similar issues have been shown in a recent study on immunity in children recovering from SAM [92], and taken together indicate the need for further research to determine the optimum criteria of discharging children that takes into account the fact that RUTF intake should not be prolonged unnecessarily given its high content of fat and other nutrients, and the need to minimize risk of relapse due to excessive morbidity. In parallel to the determination of new discharge criteria, there is a need to accelerate research aiming at determining which follow up intervention may ensure post-discharge recovery of iron homeostasis. Several studies have recently published results of interventions that can be combined with CMAM to ensure such post-discharge recovery [72, 93, 94]. With the increasing interest in ensuring long term benefits of 
SAM treatment, such interventions may contribute to the reduction of excessive morbidity observed during the first 3 months after discharge. Indeed, the high prevalence of ID and IDA among the breastfed children with SAM in this study points toward insufficient iron intake from the readily available complementary foods used by children below 5 years of age in communities where children with SAM come from [95, 96].

This study demonstrates that RUTFs should always have an appropriate density of bioavailable iron to enable reversal of ID and IDA. The FSMS-RUTF iron profile can serve as a starting point for further research and improvements that take into account the effect of cow's milk and other ingredients and factors such as phytate in the food. As an important proportion of children recovering from SAM meet anthropometric criteria for cure before reversal of their IDA, there is a need to develop an appropriate post-discharge follow up package for continuation of ID correction such as proper administration of well-formulated micronutrient powders or lipid-based nutrients supplements, anti-helminth and anti-malaria treatments, and improvements of environmental hygiene.

Our results have to be interpreted taking into account some methodological limitations. The first is that we used indicators of iron status that are influenced by inflammation and a high proportion of children enrolled into the study had inflammation at admission. To address this, we adjusted these parameters for inflammation $[58,97]$ and used the sTfr and the sTfr/ferritin index to define the iron status [98]. Studies have shown that these are less affected by inflammation and are good indicators of iron status in Malawian children [42, 56, $58,99]$ and we therefore believe that our estimates are the most precise that can practically be obtained in the absence of bone marrow or liver biopsy analysis. Although serum ferritin was also measured, we did not use this biomarker for defining iron status in this study because of the clear absence of correlation of this biomarker and anaemia in our study population. This finding was in accordance with findings from other teams showing that serum ferritin is less accurate in assessing ID in Malawian children even after adjustment for inflammation as malaria infection may lead to long lasting ferritin elevation [42, 100]. The second limitation is the absence of screening for malaria and any inherited disorders known to influence the markers of iron status or the biological regulation of iron homeostasis [16, 101-103]. This may have resulted in overestimating the prevalence of ID and IDA. However, as this study was embedded in an RCT with good randomisation at baseline, it is unlikely that this factor introduced a difference between the arms. Finally, because of financial constraints we were not able to include any analysis of the microbiota. This could have permitted a better understanding of the bacterial population of the gut at the onset and during the course of treatment and enabled us to ascertain the safety of iron densities used with regard to pathogenic gut bacterial growth and selection. Moreover, having data on microbiota changes could have allowed us to examine the influence of the microbiota on the observed difference in treatment effect on haemoglobin and iron status.

\section{Conclusion}

Our study shows that anaemia including IDA is common among children with SAM and this justifies presumptive treatment against ID and IDA in this group. The study also indicates that the FSMS-RUTF with a higher level of iron and no cow's milk is more efficacious in correcting anaemia and BIS among children with SAM than the current standard milk-based formulation and that raising the levels of iron in RUTF was not associated with any adverse outcomes.

\section{Additional files}

Additional file 1: Predictors of anaemia at admission. (DOCX $13 \mathrm{~kb}$ ) Additional file 2: Predictors of iron deficiency anaemia at admission. (DOCX $14 \mathrm{~kb}$ )

Additional file 3: Effect of treatment on haemoglobin levels in anaemic and non-anaemic children with SAM across study arms. (DOCX 14 kb)

Additional file 4: Predictors of anaemia at discharge. (DOCX $13 \mathrm{~kb}$ )

Additional file 5: Change in body iron stores (BIS) of children with SAM across study arms. (DOCX $15 \mathrm{~kb}$ )

\section{Abbreviations}

AGP: Alpha-1-acid glycoprotein; BIS: Body iron stores; Cl: Confidence interval; CMAM: Community-based management of acute malnutrition; FSMS-

RUTF: Milk-free Soybean-Maize-Sorghum based ready-to-use therapeutic food; ID: Iron deficiency; IDA: Iron deficiency anaemia; IQR: Interquartile range; ITN: Insecticide treated net; LNS: Lipid-based nutrient supplement; MCV: Mean copuscular volume; MSMS-RUTF: Milk soybean-maize-sorghum based ready-to-use therapeutic food; MUAC: Mid-upper arm circumference; OR: Odds ratio; PM-RUTF: Peanut and milk ready-to-use therapeutic food; RBC: Red blood cell count; RE: Retinol equivalents; RR: Relative risk; RUTF: Ready-to-use therapeutic food; SAM: Severe acute malnutriton; SD: Standard deviation; SMS-RUTF: Soybean-maize-sorghum based ready-touse therapeutic food; sTfR: Soluble transferrin receptor; TE: Tocopherol equivalents; WHO: World Health Organization

\section{Acknowledgements}

We thank the enumerators and their supervisors (namely, Peter Mpungalume, Gideon Kapalasa, Elizabeth Manganda, and Judith Mlenje Mkandawire) and our data entry team (Kitty Nkhwazi and Frank Damison) for their hard and excellent work. Finally, we thank Gerald Tegha of the Lilongwe research laboratory of the University of North Carolina, and the Malawi Valid Nutrition factory team (Andrew Chinguwo, Edward Mtsundano, Christopher Thipa, James Ngulube and Dalitso Odalla) for their dedication to ensuring production and distribution of study foods.

\section{Authors' contributions}

PA, PB, HM, KS, and SC: conceived the study idea, designed the SMS-RUTFs, and provided technical oversight throughout the trial, including data collection, data analysis, and preparation of this manuscript; CB, EM and SK: contributed to the study design and data collection tools development and 
implemented the data collection and entry; and all authors: contributed to the interpretation of the findings and writing of the manuscript and have read and approved the manuscript.

\section{Authors' information}

None.

\section{Funding}

The study was funded by Ajinomoto Co. Inc., the Japan International Cooperation Agency and Global Innovation Fund. Both funding organizations had no role in the study design, data collection, analysis and interpretation, or the decision to publish the findings.

\section{Availability of data and materials}

The datasets used and/or analysed during the current study are available from the corresponding author on reasonable request.

\section{Ethics approval and consent to participate}

Adherence to ethical principles has been extensively described elsewhere [32]. Briefly, the study was approved on 23rd March 2015 by the National Ethics Committee of the Malawi Ministry of Health and from Institutional Review Board of Ajinomoto Co., Inc., (Ref no. 2014-021) and was registered on 15th April 2015 in the Pan African Clinical Trial Registry (PACTR201505001101224) prior to starting recruitment. Participation was voluntary and the carer signing of the consent form confirmed the enrolment. The study was carried out in accordance with the declaration of Helsinki and adheres to CONSORT guidelines.

\section{Consent for publication}

Not applicable.

\section{Competing interests}

Valid Nutrition and Ajinomoto Co. Inc. designed and produced the SMSRUTFs. PA is an employee of Valid Nutrition and HM is an employee of Ajinomoto Co. Inc. SC is the unpaid director of Valid Nutrition and a director of Valid International Ltd. Valid International Ltd. is the sister company of Valid Nutrition, and PB and KS are Valid International employees. All other authors had no conflict of interest. Valid Nutrition administered the study grant. Valid Nutrition and Valid International researchers participated in the study design, implementation, and interpretation of the results. Apart from contributing HM's expertise, Ajinomoto Co. Inc. had no role in the study design, data collection, analysis and interpretation, or the decision to publish the findings.

\section{Author details}

${ }^{1}$ Valid Nutrition, Cuibín Farm, Derry Duff, Bantry, Co., Cork, Republic of Ireland. ${ }^{2}$ Valid International, 35 Leopold Street, Oxford OX4 1TW, UK. ${ }^{3}$ Nutrition Improvement Department, Ajinomoto Co., Inc., Tokyo, Japan. ${ }^{4} \mathrm{MOH}-$ Malawi, Lilongwe, Malawi. ${ }^{5}$ Centre de Recherche en Epidémiologie, Biostatistique et Recherche Clinique, Ecole de santé publique, Université Libre de Bruxelles, Bruxelles, Belgium.

\section{Received: 6 September 2018 Accepted: 17 June 2019}

\section{Published online: 24 June 2019}

\section{References}

1. UNICEF Suply Division. Ready to use therapeutic Food: Market Outlook: UNICEF; 2019. https://www.unicef.org/supply/files/RUTF_4_Market_and_ Supply_Update.pdf. Accessed 24 Apr 2019.

2. Estimates UWWBGJCM: WHO, World Bank Group. Levels and trends in child malnutrition in UNICEF/WHO/World Bank Group joint child malnutrition Estimates key findings of the 2016 edition. New York: UNICEF; Geneva: WHO; Washington DC: World Bank; 2018.

3. WHO, WFP, UNICEF \& UNSCN: Joint statement on the community-based management of severe malnutrition in children. 2007.

4. Briend A. Highly nutrient-dense spreads: a new approach to delivering multiple micronutrients to high-risk groups. Br J Nutr. 2001;85(Suppl 2):S175-9.

5. Briend A, Lacsala R, Prudhon C, Mounier B, Grellety Y, Golden MHN. Ready-to-use therapeutic food for treatment of marasmus [letter]. Lancet. 1999;353(9166):1767-8.

6. Golden MHN. The development of concepts of malnutrition. J Nutr. 2002;132(7):2117S-2122.
7. Briend A, Akomo P, Bahwere P, De Pee S, Dibari F, Golden MH, Manary M, Ryan K. Developing food supplements for moderately malnourished children: lessons learned from ready-to-use therapeutic foods. Food Nutr Bull. 2015;36(1 Suppl):S53-8.

8. Sevilla R, Sejas E, Zalles L, Belmonte G, Chevalier P, Parent G, Katherine H, Kolsteren P. "CLAPSEN", a global approach to the rehabilitation of severe childhood malnutrition in Bolivia. Sante. 2000;10(2):97-102.

9. Weisstaub G, Medina M, Pizarro F, Araya M. Copper, Iron, and zinc status in children with moderate and severe acute malnutrition recovered following WHO protocols. Biol Trace Elem Res. 2008;124(1):1-11.

10. Diouf S, Folquet M, Mbofung K, Ndiaye O, Brou K, Dupont C, N'Dri D, Vuillerod M, Azais-Braesco V, Tetanye E. Prevalence and determinants of anemia in young children in French-speaking Africa. Role of iron deficiency. Arch Pediatr. 2015;22(11):1188-97.

11. Kassebaum NJ, Jasrasaria R, Naghavi M, Wulf SK, Johns N, Lozano R, Regan M, Weatherall D, Chou DP, Eisele TP, et al. A systematic analysis of global anemia burden from 1990 to 2010. Blood. 2014;123(5):615-24.

12. Petry N, Olofin I, Hurrell RF, Boy E, Wirth JP, Moursi M, Donahue Angel M, Rohner F. The Proportion of Anemia Associated with Iron Deficiency in Low, Medium, and High Human Development Index Countries: A Systematic Analysis of National Surveys. Nutrients. 2016;8(11):E693.

13. Stevens GA, Finucane MM, De-Regil LM, Paciorek CJ, Flaxman SR, Branca F, Pena-Rosas JP, Bhutta ZA, Ezzati M. Nutrition impact model study G: Global, regional, and national trends in haemoglobin concentration and prevalence of total and severe anaemia in children and pregnant and non-pregnant women for 1995-2011: a systematic analysis of population-representative data. Lancet Glob Health. 2013;1(1):e16-25.

14. Allali S, Brousse V, Sacri AS, Chalumeau M, de Montalembert M. Anemia in children: prevalence, causes, diagnostic work-up, and long-term consequences. Expert Rev Hematol. 2017;10(11):1023-8.

15. Abbaspour N, Hurrell R, Kelishadi R. Review on iron and its importance for human health. J Res Med Sci. 2014;19(2):164-74.

16. McGann PT, Williams AM, McElhinney KE, Romano L, Woodall J, Howard TA, Ellis G, Mapango C, Chilima B, Ware RE, et al. Genetic causes of Anemia in Malawian children less than 5 years of age: results from the Malawi demographic and health survey. Blood. 2016;128(22):313.

17. Suchdev PS, Namaste SM, Aaron GJ, Raiten DJ, Brown KH, Flores-Ayala R, Group BW. Overview of the biomarkers reflecting inflammation and nutritional determinants of Anemia (BRINDA) project. Adv Nutr. 2016;7(2):349-56.

18. Camaschella C. Iron-deficiency anemia. N Engl J Med. 2015;372(19):1832-43.

19. Camaschella C. New insights into iron deficiency and iron deficiency anemia. Blood Rev. 2017;31(4):225-33.

20. Thakur N, Chandra J, Pemde H, Singh V. Anemia in severe acute malnutrition. Nutrition. 2014;30(4):440-2.

21. Savadogo LGB, Zoetaba I, Ilboudo B, Kinda M, Donnen P. Impact of anemia on mortality and nutritional recovery among hospitalized severely malnourished children in Burkina Faso. Open J Pediatr. 2014;4(01):115.

22. Saka A, Saka M, Ojuawo A, Abdulkarim A, Bilamin S, Latubosun L, Adeboye M. Haematological profile in children with protein energy malnutrition in north Central Nigeria. Glob J Med Res. 2012;12(4):1-7.

23. Arya AK, Lal P, Kumar P. Co-morbidities in Children with Severe Acute Malnutrition - A Tertiary Care Centre Experience. Int J Contemp Med Res. 2017;4(5):1086-8.

24. Collins S, Dent N, Binns P, Bahwere P, Sadler K, Hallam A. Management of severe acute malnutrition in children. Lancet. 2006;368(9551):1992-2000.

25. Collins S, Sadler K, Dent N, Khara T, Guerrero S, Myatt M, Saboya M, Walsh A. Key issues in the success of community-based management of severe malnutrition. Food Nutr Bull. 2006;27(3):S49-82.

26. Fondu P, Hariga-Muller C, Mozes N, Neve J, Van Steirteghem A, Mandelbaum IM. Protein-energy malnutrition and anemia in Kivu. Am J Clin Nutr. 1978;31(1):46-56.

27. Fondu P, Mandelbaum IM. Marasmic kwashiorkor anemia. III. Hemoglobin oxygen affinity. Biomedicine. 1975;22(4):291-7.

28. Yaikhomba T, Poswal L, Goyal S. Assessment of iron, folate and vitamin B12 status in severe acute malnutrition. Indian J Pediatr. 2015;82(6):511-4.

29. Borelli P, Blatt S, Pereira J, de Maurino BB, Tsujita M, de Souza AC, Xavier JG, Fock RA. Reduction of erythroid progenitors in protein-energy malnutrition. Br J Nutr. 2007;97(2):307-14.

30. Neuberger A, Okebe J, Yahav D, Paul M. Oral iron supplements for children in malaria-endemic areas. Cochrane Database Syst Rev. 2016;2:CD006589.

31. Organization WH: Guideline: daily iron supplementation in infants and children. 2016. 
32. Hurrell R, Egli I. Iron bioavailability and dietary reference values. Am J Clin Nutr. 2010;91(5):1461S-7S.

33. Cook JD, Monsen ER. Food iron absorption in human subjects. III. Comparison of the effect of animal proteins on nonheme iron absorption. Am J Clin Nutr. 1976;29(8):859-67.

34. Akomo PO, Egli I, Okoth MW, Bahwere P, Cercamondi C, Zeder C, Njage P, Owino VO. Estimated iron and zinc bioavailability in soybean-maize-sorghum ready to use foods: effect of soy protein concentrate and added phytase. J Food Process Technol. 2016;7(556). https://doi.org/10.4172/2157-7110.1000556.

35. WHO. Management of severe malnutrition: A manual for physicians and other senior health workers. Geneva: WHO; 1999.

36. Lonnerdal B. Excess iron intake as a factor in growth, infections, and development of infants and young children. Am J Clin Nutr. 2017;106(Suppl 6):1681S-7S

37. Diop EHI, Dossou NI, Ndour MM, Briend A, Wade S. Hemoglobin variations during nutrition rehabilitation of severely malnourished children with a solid or liquid diet with different level of iron; 2003.

38. Bahwere P, Balaluka B, Wells JC, Mbiribindi CN, Sadler K, Akomo P, Dramaix-Wilmet M, Collins S. Cereals and pulse-based ready-to-use therapeutic food as an alternative to the standard milk- and peanut paste-based formulation for treating severe acute malnutrition: a noninferiority, individually randomized controlled efficacy clinical trial. Am J Clin Nutr. 2016;103(4):1145-61.

39. Dostal A, Baumgartner J, Riesen N, Chassard C, Smuts CM, Zimmermann MB, Lacroix C. Effects of iron supplementation on dominant bacterial groups in the gut, faecal SCFA and gut inflammation: a randomised, placebo-controlled intervention trial in south African children. Br J Nutr. 2014;112(04):547-56.

40. Bahwere P, Akomo P, Mwale M, Murakami H, Banda C, Kathumba S, Banda C, Jere S, Sadler K, Collins S. Soya, maize, and sorghum-based ready-to-use therapeutic food with amino acid is as efficacious as the standard milk and peanut paste-based formulation for the treatment of severe acute malnutrition in children: a noninferiority individually randomized controlled efficacy clinical trial in Malawi. Am J Clin Nutr. 2017;106(4):1100-12.

41. Calis JC, Phiri KS, Faragher EB, Brabin BJ, Bates I, Cuevas LE, de Haan RJ, Phiri Al, Malange $\mathrm{P}$, Khoka $\mathrm{M}$, et al. Severe anemia in Malawian children. N Engl J Med. 2008;358(9):888-99.

42. Phiri KS, Calis JC, Siyasiya A, Bates I, Brabin B, van Hensbroek MB. New cutoff values for ferritin and soluble transferrin receptor for the assessment of iron deficiency in children in a high infection pressure area. J Clin Pathol. 2009;62(12):1103-6.

43. Cercamondi Cl, Egli IM, Mitchikpe E, Tossou F, Hessou J, Zeder C, Hounhouigan JD, Hurrell RF. Iron bioavailability from a lipid-based complementary food fortificant mixed with millet porridge can be optimized by adding phytase and ascorbic acid but not by using a mixture of ferrous sulfate and sodium iron EDTA. J Nutr. 2013;143(8):1233-9.

44. Gibson RS, Bailey KB, Gibbs M, Ferguson EL. A review of phytate, iron, zinc, and calcium concentrations in plant-based complementary foods used in low-income countries and implications for bioavailability. Food Nutr Bull. 2010;31(2 Suppl):S134-46.

45. Takehana S, Yoshida H, Ozawa S, Yamazaki J, Shimbo K, Nakayama A, Mizukoshi T, Miyano $\mathrm{H}$. The effects of pre-analysis sample handling on human plasma amino acid concentrations. Clin Chim Acta. 2016;455:68-74.

46. Erhardt JG, Estes JE, Pfeiffer CM, Biesalski HK, Craft NE. Combined measurement of ferritin, soluble transferrin receptor, retinol binding protein, and C-reactive protein by an inexpensive, sensitive, and simple sandwich enzyme-linked immunosorbent assay technique. J Nutr. 2004;134(11):3127-32.

47. Paganini D, Zimmermann MB. The effects of iron fortification and supplementation on the gut microbiome and diarrhea in infants and children: a review. Am J Clin Nutr. 2017;106(Suppl 6):1688S-93S.

48. Rhoads JM, Fatheree NY, Norori J, Liu Y, Lucke JF, Tyson JE, Ferris MJ. Altered fecal microflora and increased fecal calprotectin in infants with colic. J Pediatr. 2009;155(6):823-8 e821.

49. Bin-Nun A, Booms C, Sabag N, Mevorach R, Algur N, Hammerman C. Rapid Fecal Calprotectin (FC) Analysis: Point of Care Testing for Diagnosing Early Necrotizing Enterocolitis. Am J Perinatol. 2015;32(4):337-42.

50. Wassell J, Wallage $M$, Brewer E. Evaluation of the quantum blue(R) rapid test for faecal calprotectin. Ann Clin Biochem. 2012;49(Pt 1):55-8.

51. World Health Organization. Haemoglobin concentrations for the diagnosis of anemia and assessment of severity. Geneva: World Health Organization; 2011.

52. Sullivan KM, Mei Z, Grummer-Strawn L, Parvanta I. Haemoglobin adjustments to define anaemia. Tropical Med Int Health. 2008;13(10):1267-71.
53. Amid A, Haghi-Ashtiani B, Kirby-Allen M, Haghi-Ashtiani MT. Screening for thalassemia carriers in populations with a high rate of iron deficiency: revisiting the applicability of the Mentzer index and the effect of iron deficiency on Hb A2 levels. Hemoglobin. 2015;39(2):141-3.

54. Vehapoglu A, Ozgurhan G, Demir AD, Uzuner S, Nursoy MA, Turkmen S, Kacan A. Hematological indices for differential diagnosis of Beta thalassemia trait and iron deficiency anemia. Anemia. 2014;2014:576738.

55. Cook J. The nutritional assessment of iron status. Arch Latinoam Nutr. 1999:49(3 Suppl 2):11S-4S.

56. Engle-Stone R, Nankap M, Ndjebayi AO, Erhardt JG, Brown KH. Plasma ferritin and soluble transferrin receptor concentrations and body iron stores identify similar risk factors for iron deficiency but result in different estimates of the national prevalence of iron deficiency and iron-deficiency anemia among women and children in Cameroon. J Nutr. 2013;143(3):369-77.

57. Thurnham DI, Northrop-Clewes CA, Knowles J. The use of adjustment factors to address the impact of inflammation on vitamin a and iron status in humans. J Nutr. 2015;145(5):1137S-43S.

58. Cook JD, Flowers CH, Skikne BS. The quantitative assessment of body iron. Blood. 2003;101(9):3359-64.

59. van der Merwe LF, Eussen SR. Iron status of young children in Europe. Am J Clin Nutr. 2017;106(Suppl 6):1663S-71S.

60. Lauritsen JM, Bruus M. Epidata entry version 3.02:A comprehensive tool for validated entry and documentation of data. In: 3.02 edn: The Epidata Association; 2003.

61. STATA Corp: Stata 13 statistical software. In.: College Station, TX; 2013.

62. Kwak SK, Kim JH. Statistical data preparation: management of missing values and outliers. Korean J Anesthesiol. 2017;70(4):407-11.

63. DeSouza CM, Legedza AT, Sankoh AJ. An overview of practical approaches for handling missing data in clinical trials. J Biopharm Stat. 2009;19(6):1055-73.

64. Greenland S. Modeling and variable selection in epidemiologic analysis. Am J Public Health. 1989;79(3):340-9.

65. McLean E, Cogswell M, Egli I, Wojdyla D, de Benoist B. Worldwide prevalence of anaemia, WHO vitamin and mineral nutrition information system, 1993-2005. Public Health Nutr. 2009;12(4):444-54.

66. Nkrumah FK, Nathoo KJ, Sanders DM. Iron, folate and vitamin B12 in severe protein-energy malnutrition. Cent Afr J Med. 1988;34(3):39-43.

67. Ozkale M, Sipahi T. Hematologic and bone marrow changes in children with protein-energy malnutrition. Pediatr Hematol Oncol. 2014;31(4):349-58.

68. Ramdath DD, Golden MH. Non-haematological aspects of iron nutrition. Nutr Res Rev. 1989;2(1):29-49.

69. Sassi M. Seasonality and trends in child malnutrition: time-series analysis of health clinic data from the Dowa district of Malawi. J Dev Stud. 2015;51(12):1667-82.

70. Maleta K, Virtanen SM, Espo M, Kulmala T, Ashorn P. Childhood malnutrition and its predictors in rural Malawi. Paediatr Perinat Epidemiol. 2003;17(4):384-90.

71. Hurrell RF, Lynch SR, Trinidad TP, Dassenko SA, Cook JD. Iron absorption in humans as influenced by bovine milk proteins. Am J Clin Nutr. 1989:49(3):546-52.

72. Abbeddou S, Yakes Jimenez E, Some JW, Ouedraogo JB, Brown KH, Hess SY. Small-quantity lipid-based nutrient supplements containing different amounts of zinc along with diarrhea and malaria treatment increase iron and vitamin a status and reduce anemia prevalence, but do not affect zinc status in young Burkinabe children: a clusterrandomized trial. BMC Pediatr. 2017;17(1):46.

73. Walczyk T, Muthayya S, Wegmuller R, Thankachan P, Sierksma A, Frenken LG, Thomas T, Kurpad A, Hurrell RF. Inhibition of iron absorption by calcium is modest in an iron-fortified, casein- and wheybased drink in Indian children and is easily compensated for by addition of ascorbic acid. J Nutr. 2014;144(11):1703-9.

74. Prentice AM, Mendoza YA, Pereira D, Cerami C, Wegmuller R, Constable A, Spieldenner J. Dietary strategies for improving iron status: balancing safety and efficacy. Nutr Rev. 2017;75(1):49-60.

75. Jaeggi T, Kortman GA, Moretti D, Chassard C, Holding P, Dostal A, Boekhorst J, Timmerman HM, Swinkels DW, Tjalsma H, et al. Iron fortification adversely affects the gut microbiome, increases pathogen abundance and induces intestinal inflammation in Kenyan infants. Gut. 2015;64(5):731-42.

76. Tang M, Frank DN, Hendricks AE, Ir D, Esamai F, Liechty E, Hambidge KM, Krebs NF. Iron in Micronutrient Powder Promotes an Unfavorable Gut Microbiota in Kenyan Infants. Nutrients. 2017;9(7):E776. https://doi.org/10.3390/nu9070776.

77. Sazawal S, Black RE, Ramsan M, Chwaya HM, Stoltzfus RJ, Dutta A, Dhingra U, Kabole I, Deb S, Othman MK, et al. Effects of routine prophylactic 
supplementation with iron and folic acid on admission to hospital and mortality in preschool children in a high malaria transmission setting: community-based, randomised, placebo-controlled trial. Lancet. 2006; 367(9505):133-43.

78. Lopriore C, Guidoum Y, Briend A, Branca F. Spread fortified with vitamins and minerals induces catch-up growth and eradicates severe anemia in stunted refugee children aged 3-6 y. Am J Clin Nutr. 2004;80(4):973-81.

79. Wassell J, Dolwani S, Metzner M, Losty H, Hawthorne A. Faecal calprotectin: a new marker for Crohn's disease? Ann Clin Biochem. 2004;41(Pt 3):230-2.

80. Jones KD, Hunten-Kirsch B, Laving AM, Munyi CW, Ngari M, Mikusa J, Mulongo MM, Odera D, Nassir HS, Timbwa M, et al. Mesalazine in the initial management of severely acutely malnourished children with environmental enteric dysfunction: a pilot randomized controlled trial. BMC Med. 2014;12:133.

81. Smith MI, Yatsunenko T, Manary MJ, Trehan I, Mkakosya R, Cheng J, Kau AL, Rich SS, Concannon P, Mychaleckyj JC, et al. Gut microbiomes of Malawian twin pairs discordant for kwashiorkor. Science. 2013;339(6119):548-54.

82. Subramanian S, Huq S, Yatsunenko T, Haque R, Mahfuz M, Alam MA, Benezra A, DeStefano J, Meier MF, Muegge BD, et al. Persistent gut microbiota immaturity in malnourished Bangladeshi children. Nature. 2014;510(7505):417-21.

83. Bruzzese E, Callegari ML, Raia V, Viscovo S, Scotto R, Ferrari S, Morelli L, Buccigrossi V, Lo VA, Ruberto E, et al. Disrupted intestinal microbiota and intestinal inflammation in children with cystic fibrosis and its restoration with Lactobacillus GG: a randomised clinical trial. PLoS One. 2014;9(2):e87796.

84. Bruzzese E, Raia V, Gaudiello G, Polito G, Buccigrossi V, Formicola V, Guarino A. Intestinal inflammation is a frequent feature of cystic fibrosis and is reduced by probiotic administration. Aliment Pharmacol Ther. 2004;20(7):813-9.

85. Kerac M, Bunn J, Seal A, Thindwa M, Tomkins A, Sadler K, Bahwere P, Collins S. Probiotics and prebiotics for severe acute malnutrition (PRONUT study): a double-blind efficacy randomised controlled trial in Malawi. Lancet. 2009; 374(9684):136-44.

86. Hicks PD, Zavaleta N, Chen Z, Abrams SA, Lonnerdal B. Iron deficiency, but not anemia, upregulates iron absorption in breast-fed peruvian infants. J Nutr. 2006;136(9):2435-8.

87. Sangkhae $V$, Nemeth E. Regulation of the Iron homeostatic hormone Hepcidin. Adv Nutr. 2017;8(1):126-36.

88. Winter WE, Bazydlo LA, Harris NS. The molecular biology of human iron metabolism. Lab Med. 2014;45(2):92-102.

89. Caballero B, Solomons NW, Batres R, Torun B. Homeostatic mechanisms in the utilization of exogenous iron in children recovering from severe malnutrition. J Pediatr Gastroenterol Nutr. 1985;4(1):97-102.

90. Ashour MN, Salem SI, El-Gadban HM, Elwan NM, Basu TK. Antioxidant status in children with protein-energy malnutrition (PEM) living in Cairo, Egypt. Eur J Clin Nutr. 1999;53(8):669-73.

91. Zimmermann MB, Hurrell RF. Nutritional iron deficiency 3. Lancet. 2007; 370(9586):511-20.

92. Bahwere P, James P, Abdissa A, Getu Y, Getnet Y, Sadler K, Girma T. Use of tuberculin skin test for assessment of immune recovery among previously malnourished children in Ethiopia. BMC Res Notes. 2017;10(1):570.

93. Glinz D, Wegmuller R, Ouattara M, Diakite VG, Aaron GJ, Hofer L, Zimmermann MB, Adiossan LG, Utzinger J, N'Goran EK, et al. Iron Fortified Complementary Foods Containing a Mixture of Sodium Iron EDTA with Either Ferrous Fumarate or Ferric Pyrophosphate Reduce Iron Deficiency Anemia in 12- to 36-Month-Old Children in a Malaria Endemic Setting: A Secondary Analysis of a Cluster-Randomized Controlled Trial. Nutrients. 2017;9(7):759. https://doi.org/10.3390/nu9070759.

94. Menon P, Ruel MT, Loechl CU, Arimond M, Habicht JP, Pelto G, Michaud L. Micronutrient sprinkles reduce anemia among 9- to 24-mo-old children when delivered through an integrated health and nutrition program in rural Haiti 4. J Nutr. 2007;137(4):1023-30.

95. Dube K, Schwartz J, Mueller MJ, Kalhoff $\mathrm{H}$, Kersting M. Iron intake and iron status in breastfed infants during the first year of life. Clin Nutr. 2010;29(6):773-8.

96. Eneroth $\mathrm{H}, \mathrm{El}$ AS, Persson LA, Kabir I, Lonnerdal B, Hossain MB, Ekstrom EC. Duration of exclusive breast-feeding and infant iron and zinc status in rural Bangladesh. J Nutr. 2009;139(8):1562-7.

97. Thurnham DI, McCabe LD, Haldar S, Wieringa FT, Northrop-Clewes CA, McCabe GP. Adjusting plasma ferritin concentrations to remove the effects of subclinical inflammation in the assessment of iron deficiency: a metaanalysis. Am J Clin Nutr. 2010;92(3):546-55
98. Thurnham DI, Northrop-Clewes CA. Inflammation and biomarkers of micronutrient status. Curr Opin Clin Nutr Metab Care. 2016;19(6):458-63.

99. Cichon B, Ritz C, Fabiansen C, Christensen VB, Filteau S, Friis H, Kaestel P. Assessment of regression models for adjustment of Iron status biomarkers for inflammation in children with moderate acute malnutrition in Burkina Faso. J Nutr. 2017;147(1):125-32.

100. Castberg FC, Sarbah EW, Koram KA, Opoku N, Ofori MF, Styrishave B, Hviid L, Kurtzhals JAL. Malaria causes long-term effects on markers of iron status in children: a critical assessment of existing clinical and epidemiological tools. Malar J. 2018;17(1):464.

101. Foote EM, Sullivan KM, Ruth LJ, Oremo J, Sadumah I, Williams TN, Suchdev PS. Determinants of anemia among preschool children in rural, western Kenya. Am J Trop Med Hyg. 2013;88(4):757-64.

102. Barker MK, Henderson AM, Naguib K, Vercauteren SM, Devlin AM, Albert AY, Bahizire E, Tugirimana PL, Akilimali PZ, Boy E, et al. Serum soluble transferrin receptor concentrations are elevated in Congolese children with Glucose-6phosphate dehydrogenase variants, but not sickle cell variants or alphathalassemia. J Nutr. 2017;147(9):1785-94.

103. Engle-Stone R, Williams TN, Nankap M, Ndjebayi A, Gimou MM, Oyono Y, Tarini A, Brown KH, Green R. Prevalence of Inherited Hemoglobin Disorders and Relationships with Anemia and Micronutrient Status among Children in Yaounde and Douala, Cameroon. Nutrients. 2017;9(7):E963. https://doi.org/ 10.3390/nu9070693.

\section{Publisher's Note}

Springer Nature remains neutral with regard to jurisdictional claims in published maps and institutional affiliations.
Ready to submit your research? Choose BMC and benefit from:

- fast, convenient online submission

- thorough peer review by experienced researchers in your field

- rapid publication on acceptance

- support for research data, including large and complex data types

- gold Open Access which fosters wider collaboration and increased citations

- maximum visibility for your research: over $100 \mathrm{M}$ website views per year

At BMC, research is always in progress.

Learn more biomedcentral.com/submissions 